\title{
Recurrent Masses after Testicular Cancer: Growing Teratoma Syndrome. A Case Report and Review of the Literature
}

\author{
Fanny Priod $^{\mathrm{a}}$ Francis Lorge $^{\mathrm{b}} \quad$ Marcelo Di Gregorio $^{\mathrm{b}}$ \\ Michaël V. Dupont ${ }^{c}$ Marie-Cécile Nollevaux ${ }^{d}$ Laurence Faugeras $^{a}$ \\ Georges Lawson ${ }^{\mathrm{e}}$ Philippe Eucher ${ }^{\mathrm{f}}$ Lionel D'Hondt ${ }^{\mathrm{a}}$ \\ ${ }^{a}$ Department of Oncology, CHU UCL Namur, Yvoir, Belgium; ${ }^{b}$ Department of Urology, CHU \\ UcL Namur, Yvoir, Belgium; 'Department of Radiology, CHU UCL Namur, Yvoir, Belgium; \\ ${ }^{\mathrm{d}}$ Department of Anatomopathology, CHU UcL Namur, Yvoir, Belgium; ${ }^{\mathrm{e}}$ Department of Ear

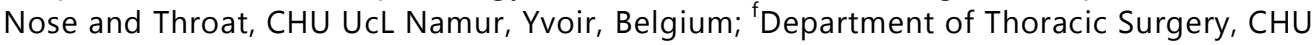 \\ UCL Namur, Yvoir, Belgium
}

\section{Keywords}

Growing teratoma syndrome $\cdot$ Nonseminomatous germ cell tumor $\cdot$ Testis

\begin{abstract}
Background: Growing teratoma syndrome is a rare syndrome that affects patients with nonseminomatous germ-cell tumors (NSGCTs). It is characterized by recurrent growing masses that appear during or after chemotherapy in the presence of normal levels of tumor markers. Histological examination is the only way to confirm the diagnosis. Case Presentation: We present the case of a 36-year-old man who developed recurrent masses after curative treatment for NSGCT of the testicle. His tumor markers were normal. The patient was cured after multiple surgical procedures. Conclusions: Close follow-up after treatment for NSGCT is very important for early detection of this syndrome, which can occur even many years after tumor onset. Normal blood makers can be misleading, and surgery remains the only curative treatment.

(C) 2017 The Author(s)

Published by S. Karger AG, Basel
\end{abstract}


 Oncology}

\section{Introduction}

Nonseminomatous germ-cell tumors (NSGCTs) affect young adults, with the peak incidence occurring between the ages of 20 and 35 years. NSGCTs represent $1 \%$ of all malignancies in men. With modern treatments, the prognosis is usually good, but it varies according to tumor histology, stage, and serum markers [1]. Although rare, masses that appear during or after treatment of NSGCTs are usually tumor relapses. In rare cases, these masses can have another cause, such as growing teratoma syndrome (GTS), which was first described in 1982 [2]. This syndrome, which occurs predominantly in young adults, affects patients treated for NSGCT. GTS is characterized by recurrent growing masses that appear during or after chemotherapy. Tumor markers are usually normal, but histological examination shows elements that are characteristic of mature teratoma. Complete resection is the only curative treatment. It is important that this rare entity is found and correctly diagnosed as early as possible, since the prognosis is usually excellent with specific and appropriate radical surgical treatment.

\section{Case Report}

A 36-year-old man who was a professional soldier consulted his general practitioner several times for intermittent left testicular pain. The clinical diagnosis was epididymitis, but treatment with antibiotics and NSAID therapy was not effective. Clinical and radiological examination performed by a urologist revealed a suspect mass in the left testis. Left radical orchidectomy was performed in September 2009, and histological evaluation revealed a diagnosis of a $2.2-\mathrm{cm}$ teratoma that was associated with malignant intratubular germinal cells and syncytiotrophoblastic cells. The pathological staging was pT1 pNx pMx. Serum tumor marker analysis at diagnosis showed normal lactate dehydrogenase $(579 \mathrm{IU} / \mathrm{L}$; normal, 313-618 IU/L), elevated $\beta$-HCG $(126.6 \mathrm{mIU} / \mathrm{mL}$; normal, $<5.0 \mathrm{mIU} / \mathrm{mL})$, and normal $\alpha-$ fetoprotein $(5.5 \mathrm{ng} / \mathrm{mL})$ levels. Liver and renal function tests, electrolytes, and complete blood count were all normal.

Thoracic and abdominal computed tomography (CT) revealed left paratracheal nodes (11 mm) (Fig. 1) and left lomboaortic nodes (19 mm). Adjuvant chemotherapy was administrated after the total radical left orchidectomy due to postoperative $\beta$-HCG positivity of 12.9 $\mathrm{mIU} / \mathrm{mL}$ plus the presence of left lomboaortic lymph nodes. The patient received 2 cycles of BEP (bleomycin, etoposide, cisplatin) chemotherapy followed by a retroperitoneal lymphadenectomy since the lymph nodes were still present after chemotherapy. The serum tumor marker $\beta$-HCG normalized after chemotherapy. Histological examination of the surgical retroperitoneal resection specimen revealed teratomatous tissue in a $4.5-\mathrm{cm}$ polycystic mass without any residual nodal invasion (Fig. 2).

Three months later, a CT scan revealed new mediastinal enlarged lymph nodes. The patient was asymptomatic and his serum marker levels were normal. A 2-cm teratoma was removed by thoracotomy. Three months after that, the CT scan showed a new cervical mass (Fig. 3) which was surgically removed and again showed teratomatous tissue (Fig. 4). Two months later, a new 5-cm cervical mass (Fig. 5) appeared, and surgery was performed once more. Histological examination again revealed a mature teratoma. The patient suffered from postoperative left Bernard-Horner syndrome. He now undergoes regular follow-up every 6 months by clinical examination and CT and remains disease free more than 4 years after his last surgery. He has recovered completely from Bernard-Horner syndrome. 


\section{Discussion}

GTS is defined as tumor mass growth in the retroperitoneum or in locations such as the pelvis, abdomen, chest, liver, or bone. This syndrome occurs during or after chemotherapy in patients with NSGCT of the testis or ovary. The incidence of GTS ranges from 1.9 to $7.6 \%$ [2], with some cases reported up to 12 years after the end of chemotherapy. This syndrome disproportionately affects young adults due to the epidemiology of the underlying NSGCT pathology. The 5-year overall survival is usually good (89-90\%) [3].

The pathogenesis of GTS is unknown. One hypothesis is that chemotherapy selects teratoma cells or induces the transformation of malignant cells to benign cells [4]. GTS is defined by 3 criteria: the presence of enlarging masses during or after chemotherapy; the normalization of previously elevated serum tumor markers; and histologically mature teratoma as observed by microscopy. One report of the therapy and follow-up of 33 patients suggests that the following are predisposing factors for developing GTS: the presence of mature teratoma in the primary tumor; no size reduction in metastases or in their growth during chemotherapy; the presence of mature teratoma tissue in postchemotherapy residual masses; and incomplete resection after chemotherapy [3]. Our case had the first 3 factors.

Mature teratoma is resistant to chemotherapy and radiotherapy. Some systemic therapies have demonstrated activity in inoperable cases. For example, in 1 case, mass enlargement was temporarily stabilized using interferon [5]. Bevacizumab can also lead to clinical improvement and can stabilize the residual mass [6]. However, in this case, when treatment with bevacizumab was stopped, there was always disease progression.

A phase 1 trial published in 2009 studied 3 patients with GTS who received an oral drug that selectively inhibits CDK4/6 (PD0332991) [7]. CDK4/6 stimulates cell growth by phosphorylating retinoblastoma protein (pRB). Mature teratomas express high levels of $\mathrm{pRB}$, so CDK4/6 selective inhibitors may be an option for treating inoperable GTS. In the trial, all patients had stable disease for almost 2 years, so this drug could be a therapeutic alternative for inoperable patients.

Currently, radical surgery is the only curative treatment for GTS. The surgery must be complete and adequate since this determines the prognosis. GTS recurrence is observed in $72-83 \%$ of patients with incomplete resection while recurrence is $0-4 \%$ with complete resection [2]. If there is a late diagnosis or incomplete resection, the prognosis may be worse because of the compression of adjacent structures such as vital organs or vessels, the development of pain syndrome due to a mass effect, or higher operative morbidity. Malignant teratoma transformation has been reported in rare cases (about 3\%) [8]. NSGCT, adenocarcinoma, sarcoma, primitive neuroectodermal tumor, and carcinoid tumor have all been described and should be considered for the differential diagnosis.

In conclusion, it is very important to clearly identify and diagnose GTS as early as possible and to provide curative complete resection of the masses. Our case demonstrates that an aggressive surgical approach with multiple surgical procedures is sometimes required to cure patients with GTS. Regular and continued follow-up is critical in the management of patients with NSGCT because GTS can occur several years after chemotherapy.

\section{Statement of Ethics}

Written informed consent was obtained from the patient for publication of this case report and any accompanying images. 


\section{Case Reports in Oncology}

\begin{tabular}{l|l}
\hline Case Rep Oncol 2017;10:910-915 \\
\hline DOI: 10.1159/000481397 & $\begin{array}{l}\text { ○ 2017 The Author(s). Published by S. Karger AG, Basel } \\
\text { www.karger.com/cro }\end{array}$ \\
\hline
\end{tabular}

Priod et al.: Recurrent Masses after Testicular Cancer: Growing Teratoma Syndrome. A Case Report and Review of the Literature

\section{Disclosure Statement}

The authors have no conflicts of interest to declare.

\section{References}

1 Gorbatiy V, Spiess P, Pisters L: The growing teratoma syndrome: current review of the literature. Indian J Urol 2009;29:186-189.

-2 Ananya P, Devasenathipapathy K, Chandrashekhara SH, Manisha J: Growing teratoma syndrome of ovary: avoiding a misdiagnosis of tumour recurrence. J Clin Diagn Res 2014;8:197-198.

-3 André F, Fizazi K, Culine S, Droz J, Taupin P, Lhommé C, Terrier-Lacombe M, Théodore C: The growing teratoma syndrome: results of therapy and long-term follow-up of 33 patients. Eur J Cancer 2000;36:1389-1394.

4 Kiyosumi S, Hiroaki K, Fumitaka K: Growing teratoma syndrome of the ovary showing three patterns of metastasis: a case report. Case Rep Oncol 2013;6:544-549.

-5 Rustin GJ, Kaye SB, Williams CJ, Newlands ES, Bagshawe KD, Toy JL: Response of differentiated but not anaplastic teratoma to interferon. Br J Cancer 1984;50:611-616.

-6 Mego M, Reckova M, Sycova-Mila Z, Obertova J, Brozmanova K, Salek T, Mardiak J: Bevacizumab in a growing teratoma syndrome. Case report. Ann Oncol 2007;18:962-963.

7 Vaughn DJ: Treatment of growing teratoma syndrome. N Engl J Med 2009;360:423-424.

-8 Kampan N, Trika I, Arifuddin D, Lim Pei S, Mohd Hashim 0, Ahmad Zailani Hatta Mohd D: Growing teratoma syndrome. A rare case report and review of the literature. Case Rep Obstet Gynecol 2012;2012:134032.

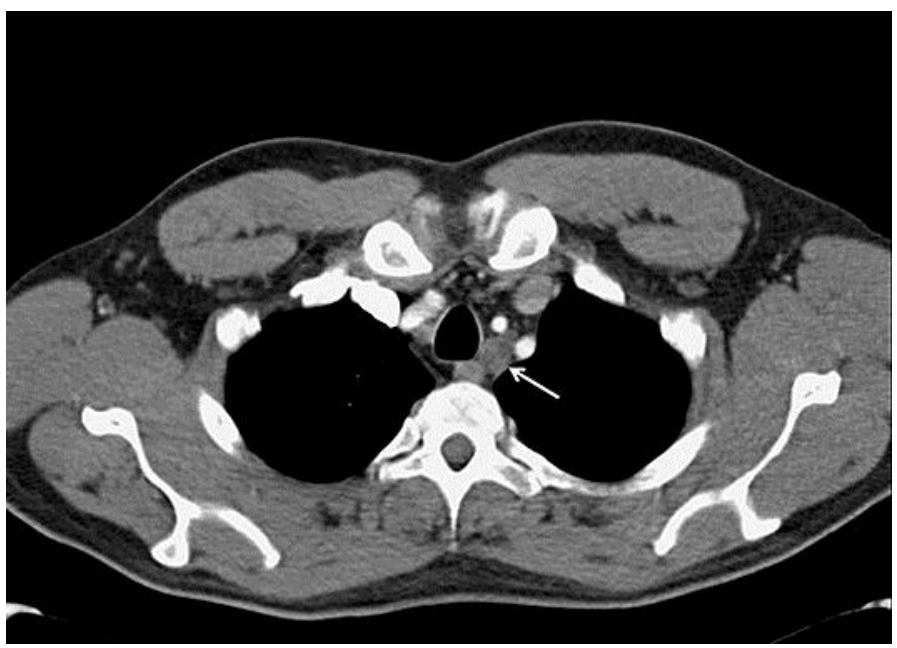

Fig. 1. Axial contrast-enhanced computed tomography at the level of the trachea was performed for the initial staging. An enlarged and ill-defined lymph node is present on the left side of the trachea (white arrow). 


\section{Case Reports in Oncology}

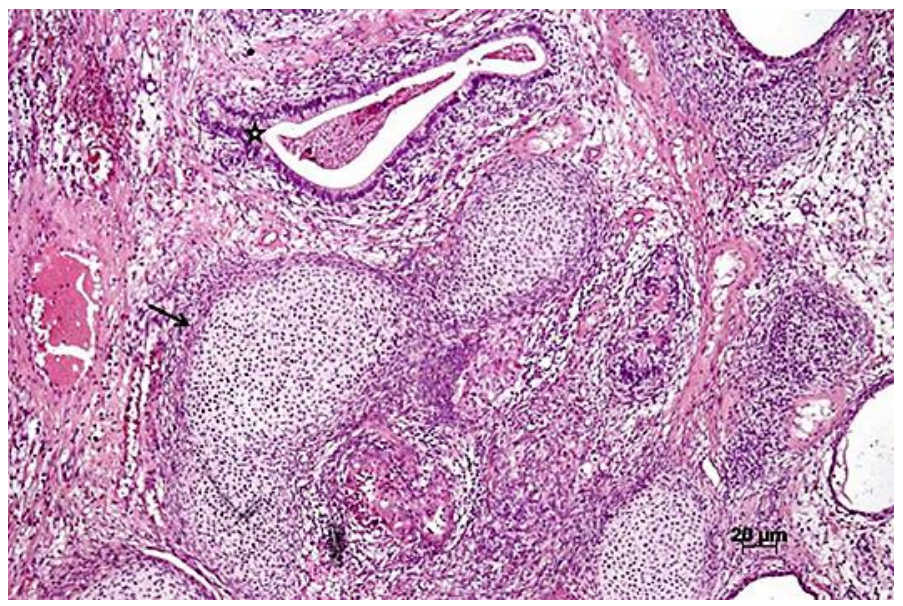

Fig. 2. Microscopic findings of the resected tumor. The teratoma had various types of immature tissue. The black arrow indicates a mesodermal component (cartilaginous tissue), and the black star indicates a glandular structure. Hematoxylin-eosin staining. Magnification, $\times 5$.

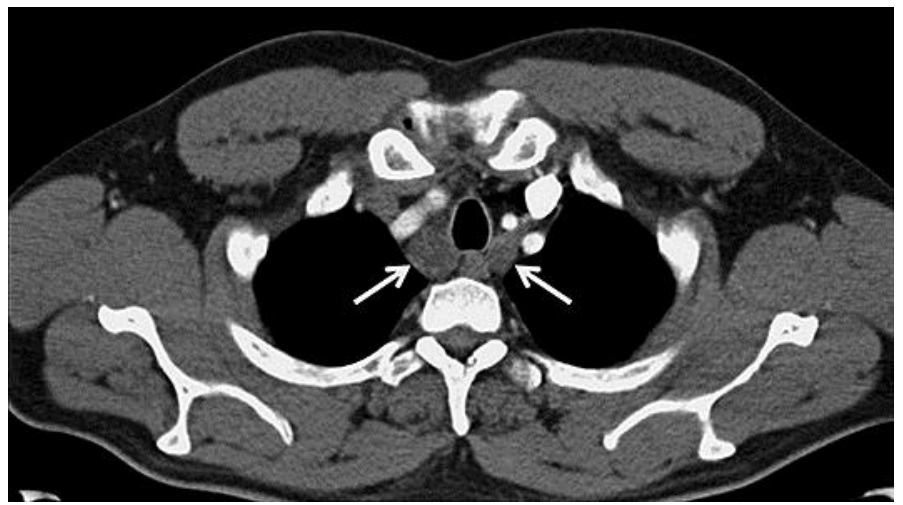

Fig. 3. Axial contrast-enhanced computed tomography at the level of the trachea was performed 9 months after the diagnosis. Enlarged lymph nodes are present on the right and left sides of the trachea (white arrows). 


\section{Case Reports in Oncology}

www.karger.com/cro

Priod et al.: Recurrent Masses after Testicular Cancer: Growing Teratoma Syndrome. A Case Report and Review of the Literature

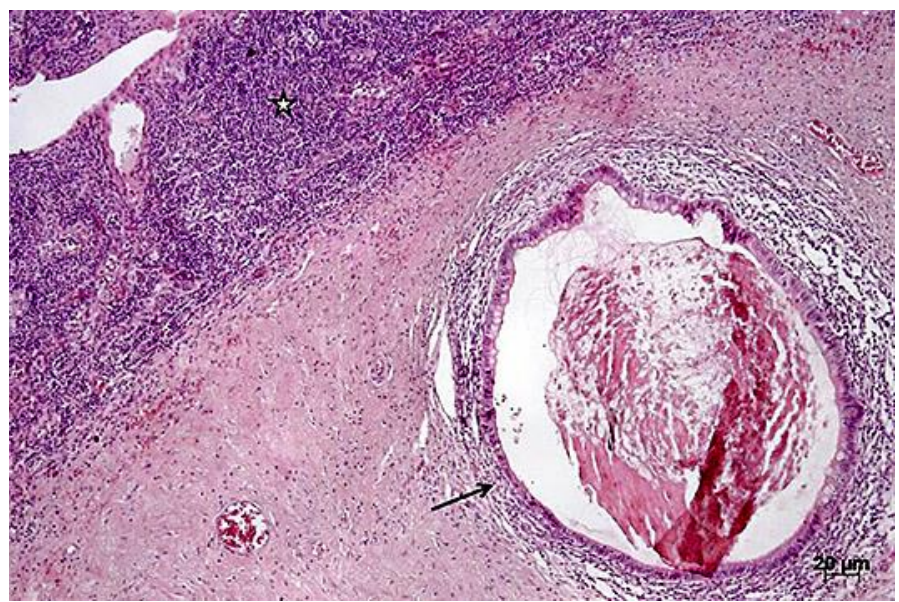

Fig. 4. Metastatic teratomatous tissue can be seen within the lymph node tissue (black star) as revealed by the presence of glandular tissue (black arrow). Hematoxylin-eosin staining. Magnification, $\times 5$.

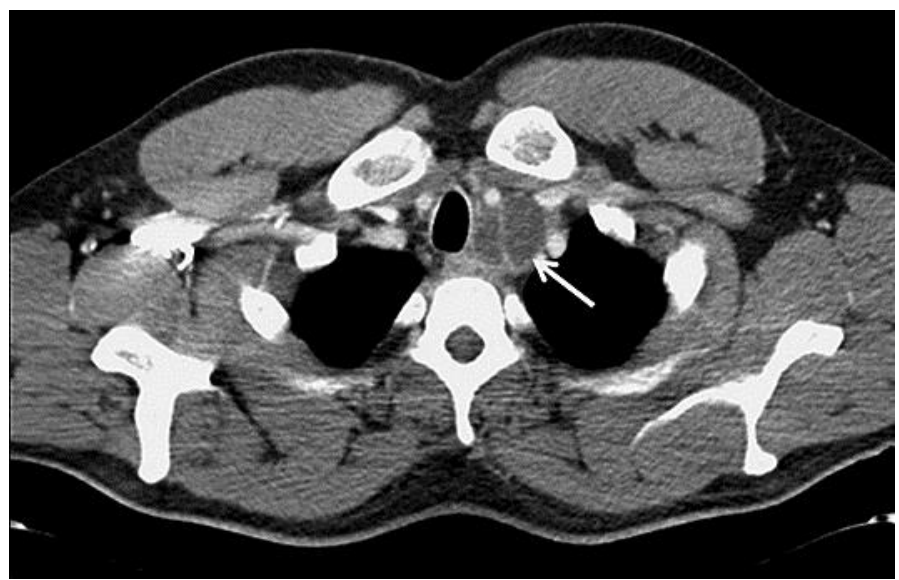

Fig. 5. Axial contrast-enhanced computed tomography at the level of the trachea was performed 22 months after the diagnosis. An enlarged and necrotic lymph node is present on the left side of the trachea (white arrow). 